\title{
Family Support Groups for family members of mentally ill offenders: A pilot
}

study

Sara Rowaert $^{1}$, Stijn Vandevelde ${ }^{2}$, Kurt Audenaert $^{3}$, \& Gilbert Lemmens ${ }^{4}$

${ }^{1}$ Department of Special Needs Education, H. Dunantlaan 2, Ghent University, Belgium; Sara.Rowaert@UGent.be (PhD)

${ }^{2}$ Department of Special Needs Education, H. Dunantlaan 2, Ghent University, Belgium; Stijn.Vandevelde@UGent.be (PhD)

${ }^{3}$ Department of Psychiatry and Medical Psychology, De Pintelaan 185, Ghent University, Belgium; Kurt.Audenaert@UGent.be (MD, PhD)

${ }^{4}$ Department of Psychiatry and Medical Psychology, De Pintelaan 185, Ghent University, Belgium; Gilbert.Lemmens@UGent.be (MD, PhD)

*Requests for reprints should be addressed to Sara Rowaert, Ghent University, Department of Special Needs Education, H. Dunantlaan 2, B-9000 Ghent (e-mail: Sara.Rowaert@UGent.be; tel.: +32 933103 11). 


\begin{abstract}
To date, there is a lack of family interventions for family members of persons with a mental illness who offended (PMIO). With the aim of addressing this issue, a Family Support Group (FSG) has been developed. The current pilot study investigated the impact of two pilot FSGs for family members of PMIO in relation to quality of life, burden, coping strategies, and resilience. Family members completed several questionnaires (i.e. WHOQOL-BREF, ZBI-22, CERQ, RS-nl) both before and after the group intervention. A total of 20 family members participated in both FSGs. The results indicated that participants experienced less self-blame, a decrease in loss of control over their lives, and improved emotional well-being. The findings showed that attending an FSG can be empowering for family members as it offers support in the management of emotional experiences and coping strategies.
\end{abstract}

\title{
Keywords
}

Family Support Group; Family members; Persons with a mental illness who offended 


\section{Introduction}

Family members of persons with a mental illness who offended (PMIO) often play an important role in their relative's life, which may seriously impact upon their own well-being (Rowaert et al., 2016). Research has shown that family members struggle with feelings of anxiety, powerlessness, and grief (Nordström, , Kullgren, \& Dahlgren, 2006; Rowaert et al., 2016). As society tends to doubly stigmatise PMIO through the application of constructs including that of 'psychiatric patient' and 'criminal', they frequently experience guilt and shame, and feel socially isolated (Absalom-Hornby, Gooding, \& Tarrier, 2011; Pearson \& Tsang, 2004; Rowaert et al., 2016; Rowaert, Vandevelde, Lemmens, \& Audenaert, 2017; Tsang et al., 2002). Family members reportedly struggle with feelings of (self-)blame which often exacerbates their perceived burdens and diminishes their sense of hopefulness (Moses, 2010). Furthermore, they may feel both inadequate and intimidated in their role as caregiver, which is associated with poorer psychological well-being and which may affect their lifecourse and identity (Moses, 2010; Ridley et al., 2014). In general, family members of PMIO report a poorer quality of life, increased stress as well as emotional, financial, and psychosocial burdens compared to families of mentally ill individuals (Ferriter \& Huband, 2003; McCann, McKeown, \& Porter., 1996; Marsh \& Johnson, 1997; Nordström et al., 2006; Tsang, Pearson, \& Yuen, 2002). They often receive little support from friends, family, and professionals, although research has shown that family support plays a critical role in alleviating feelings of self-blame (McCann et al., 1996; Moses, 2010; Nordström et al., 2006; Ridley et al., 2014).

Mechanisms that are intended to improve social contact and to reduce stigma and shame are already included in family interventions for family members of mentally ill relatives (Wasserman, Weisman de Mamani, \& Suro, 2012). Such family interventions can assist family members in helping them to explore their fears and in allowing them to develop 
new and hopeful narratives with regard to their situation (Moses, 2010). Despite the fact that family interventions for psychiatric disorders are common practice and recommended by most guidelines, such as The National Institute for Health and Care Excellence [NICE] guidelines, only a minority of reported family interventions have thus far focused specifically on the needs and experiences of family members of PMIO (Absalom, McGovern, Gooding, \& Tarrier, 2010; Absalom-Hornby et al., 2011; Geelan \& Nickford, 1999). Consequently, the researchers of the present study developed a Family Support Group (FSG) intervention to support family members who are dealing with a person with a mental illness who offended (Rowaert, Hanssens, Audenaert, Vandevelde \& Lemmens, submitted). The aim of this pilot study was to investigate the effects of the FSG on quality of life, experience of burdens, coping strategies, and resilience of family members.

\section{Methodology}

\section{Sample Selection}

Participants were recruited through the distribution of an information leaflet in several locations in Flanders (e.g. (forensic) psychiatric facilities, prisons, non-profit organizations for family members of persons with a mental illness, and outpatient mental health services). Flanders is located in the Dutch speaking and northern part of Belgium. Until recently, the availability of forensic psychiatric care in Flanders was limited, which resulted in high incarceration rates in penitentiary facilities of persons with a mental illness who offended (Vandevelde et al., 2011). Since two decades, a continuum of forensic psychiatric care is organised, comprising several specialised forensic care units or services of general psychiatric hospitals, community based services and two Forensic Psychiatric Centres (FPC).

The inclusion criteria required that participants in the FSG were: (1) a family member of a mentally ill offender who has been mandated to care under a current or past internment 
measure ${ }^{i}$ and who has received a diagnosis of schizophrenia, psychotic or bipolar disorder, and (2) of age 18 or older. A group cycle commenced after six family members provided their informed written consent to participate in the study.

The pilot study was approved by the Ethics Committee of Ghent University Hospital (EC decision: B670201526897).

\section{Participants}

A total of 20 family members participated in two FSGs. All participants were Caucasian and Dutch speaking and were living across different regions in Flanders. The mean age of the participants was 59.5 years (Standard Deviation (SD): 12.66, range: 28-75). Participant characteristics of each group cycle are described in Table 1. Three participants withdrew from the FSG. Within the first group cycle, one participant did not attend any session. Two participants withdrew from the second group cycle, following the first and second sessions, respectively. On average, participants took part in 3.2 sessions (SD: 1.6, range 1-4)

[Insert table 1 approximately here]

\section{Organisation of the Family Support Groups}

The treatment protocol of the FSG is described extensively in another article (Rowaert et al., submitted). The aim of the FSG was to support the family members of PMIO in managing the implications of both psychiatric problems and the internment measure of a relative. An FSG cycle consisted of four group sessions. The first three sessions were conducted fortnightly, with the fourth session being held one month following the third session. The sessions were approximately 120 minutes in duration. A coffee break was permitted after 90 minutes. Each session was audio- and video-recorded, and was similarly structured with a go-round, group discussion, break, and therapeutic reflection. The first session commenced with an 
introduction outlining the organisation of the FSG and its rules. Furthermore, the first session focused on the impact of mental illness and the internment measure on the family members' lives. The following sessions focused on self-care rather than on care for the relative (session 2), and addressed the strengths and capabilities required to cope with the situation (session 3). The final session (session 4) consisted in a reflection on previous sessions as well as on the future. The group sessions were directed by 2 psychiatrists, namely, a forensic psychiatrist and an experienced multi-family therapist. The therapists stimulated the exchange of experiences, and pointed to similarities and differences in the stories of the family members.

Following session 2, 3, and 4, homework assignments were given (e.g. family members were asked to do something for themselves during the following two weeks that they usually do not, and which constituted an indulgence).

An observation team followed the groups after a one-way screen. The first group cycle included the first author of this paper (i.e. the main researcher of the study) and two masterlevel students in Special Needs Education from Ghent University. The second group cycle included the researcher and a medical resident in Psychiatry from the Department of Psychiatry and Medical Psychology at Ghent University Hospital.

\section{Data Collection}

The participants were asked to complete a battery of questionnaires a week before the commencement of the FSG (T0) and one week following the final session (T1). The questionnaires assessed quality of life (WHOQOL-BREF), experienced burden (Zarit Burden Interview; ZBI-22), cognitive coping strategies (Cognitive Emotion Regulation Questionnaire; CERQ) and resilience (Resilience Scale Dutch Version; RS-nl 25) of the participants. 


\section{Quality of Life}

The World Health Organization Quality of Life Instrument (WHOQOL-BREF), Dutch version (De Vries \& Van Heck, 1996), is a 26-item questionnaire that measures Quality of Life (QoL). Two items are scored separately and are used to indicate a participant's overall perception of quality of life and health: (1) "How would you rate your QoL?” (range: 1 ['very poor'] to 5 ['very good']; and (2) "How satisfied are you with your health?" (range: 1 ['very dissatisfied'] to 5 ['very satisfied']. Furthermore, the WHOQOL-BREF contains four different domains ranging from 1 ['very poor'] to 5 ['very good']: (1) Physical health (seven items; Cronbach alpha in this study: $\alpha \_$pre $=.87, \alpha \_$post $\left.=.86\right),(2)$ Psychological health (six items; $\alpha \_$pre $=.81, \alpha \_$post $\left.=.90\right),(3)$ Social relationships $\left(\right.$ three items; $\alpha \_$pre $=.74, \alpha \_$post $=$ .43 ) and (4) Environment (eight items; $\alpha \_$pre $=.90, \alpha \_$post $=.80$ ). Domain scores range from 0-100 with higher scores indicating a better QoL (THE WHOQOL GROUP, 1995; THE WHOQOL GROUP, 1998). Given the poor internal consistency $(<0.50)$ on the post-score of 'social relationships', this domain was omitted from the analysis.

\section{Experienced Burdens}

The Zarit Burden Interview (ZBI-22) (Zarit, Reever, Bach-Peterson., 1980; 1986; Mapi Research Trust, 2014) is a subjective measure of the caregiver's burden, and consists of 22 items. Twenty-one items are summed to produce a total burden score, measured on a scale ranging from 0 ['never'] to 4 ['nearly always'] (Cronbach alpha in this study: $\alpha \_$pre $=.90$, $\alpha \_$post $=.93$ ). Item 22 represents an overall burden, and is scored from 0 ['not at all'] to 4 ['extremely']. It reflects five different domains (Rankin, Haut, Keefover \& Franzen, 1994):

(1) Burden in the relationship (six items; $\alpha \_$pre $=.65, \alpha \_$post $=.0 .77$ ), (2) Emotional wellbeing (seven items; $\alpha \_$pre $=0.84, \alpha \_$post $=0.86$ ), (3) Social and family life (four items; $\alpha \_$pre $=0.79, \alpha \_$post $\left.=0.80\right),(4)$ Finances (one item) and (5) Loss of control over one's life (four 
items; $\alpha \_$pre $=0.68, \alpha \_$post $\left.=0.81\right)$. Higher scores indicate that caregivers experience a greater burden (Mapi Research Trust, 2014).

\section{Coping Strategies}

The Cognitive Emotion Regulation Questionnaire (CERQ) is a Dutch self-report instrument consisting of 36 items measured on a scale ranging from 1 ['almost never'] to 5 ['almost always']. The CERQ refers to nine cognitive coping strategies commonly utilised following a confrontation with a threatening or stressful event. Each coping strategy is measured with reference to 4 items: (1) Self-blame (Cronbach alpha in this study: $\alpha \_$pre $=.72$, $\alpha \_$post $=.60$ ), (2) Other-blame $\left(\alpha \_\right.$pre $=.51, \alpha \_$post $\left.=.71\right)$, (3) Rumination or focus on thought $\left(\alpha \_\right.$pre $=.61$, $\alpha \_$post $\left.=.90\right),(4)$ Catastrophising $\left(\alpha \_\right.$pre $=.78, \alpha \_$post $\left.=.78\right),(5)$ Putting into perspective $\left(\alpha \_\right.$pre $=.81, \alpha \_$post $\left.=.88\right),(6)$ Positive refocusing $\left(\alpha \_\right.$pre $=.74, \alpha \_$post $\left.=.74\right),(7)$ Positive reappraisal $\left(\alpha \_\right.$pre $=.78, \alpha \_$post $\left.=.76\right),(8)$ Acceptance $\left(\alpha \_\right.$pre $=.86, \alpha \_$post $\left.=.82\right)$ and $(9)$ Refocusing on planning $\left(\alpha \_\right.$pre $=.65, \alpha \_$post $\left.=.54\right)$. Higher scores suggest an increased likelihood that the associated coping strategy will be utilised (Garnefski, Kraaij, \& Spinhoven, 2006; Garnefski \& Kraaij, 2007). Given the poor internal consistency $(<0.55)$ of 'other blame' and 'refocusing on planning', these domains were omitted from the analysis.

\section{Resilience}

The Resilience Scale Dutch Version (RS-nl 25) (Portzky, Wagnild, De Bacquer, Audenaert., 2010 ) is a self-report instrument consisting of 25 items (Cronbach alpha in this study: $\alpha \_$pre $=$ $.86, \alpha \_$post $\left.=.77\right)$ with scores ranging from 1 ['strongly disagree'] to 4 ['strongly agree'] to produce a total resilience score. The scale is subdivided into two subscales: (1) Personal Competence $\left(17\right.$ items; $\alpha \_$pre $=.86, \alpha \_$post $\left.=.78\right)$ and (2) Acceptance of Life and Self (eight items; $\alpha \_$pre $=.51, \alpha \_$post $\left.=.17\right)$. Given the poor internal consistency $(<0.50)$ of the latter 
scale with regard to both pre- and post-treatment, only the total score and the scores on the 'Personal Competence' scale have been analysed. Higher scores indicate greater levels of resilience (Portzky et al., 2010).

\section{Data Analysis}

Statistical analysis was performed using SPSS 23 with $p<0.05$ as the standard determining statistical significance. To verify a normal distribution of the data, the Shapiro-Wilk test was utilised. Questionnaire data was analysed using Linear Mixed Model analysis (LMM). All 20 participants were studied for baseline measures (T0) and were thus included in the Linear Mixed Model analysis. The independent variable time was entered into the model as a fixed effect. Intercepts were considered to be fixed effects. Post hoc pairwise comparisons were computed using Bonferroni correction for multiple comparisons. Residual analysis was performed to assess model adequacy.

\section{Results}

With regard to the ZBI-22, family members showed improved emotional well-being $(\mathrm{F}[1,165]$ $=7.643, \mathrm{p}<0.05)$ with a mean difference of $-1.1995 \%$ confidence interval $(\mathrm{CI})[-2.09$ to $-0.28]$ as well as a decrease in loss of control over one's life $(F[1,163]=4616, p<0.05)$ with a mean difference of $-0.8695 \%$ CI $[-1.0$ to -0.01$]$. Furthermore, results from the CERQ showed that family members experienced a decrease in self-blame $(F[1,169]=5.493, p<$ $0.05)$ with a mean difference of $-1.4195 \% \mathrm{CI}[-2.68$ to -0.14$]$. When compared to the norm scores, a similar result can be found, suggesting that family members engage in more selfblame than the norm during pre-treatment whereas they engage in less self-blame than the norm post-treatment (see Table 2). 
The alternative scales did not produce any significant results. However, comparing the norm scores of the CERQ with the results of this study, the results suggested that family members are more likely to utilise the following coping strategies: acceptance, rumination or focus on thoughts, positive refocusing, putting into perspective, and catastrophising. Only positive reappraisal is lower than the norm, decreasing progressively post-treatment. Evaluating the norm scores of the RS-nl with the results of the current study, family members score considerably lower. With reference to the personal competence scale, the scores indicated in the present study are almost equal to the norm.

[Insert table 2 approximately here]

\section{Discussion}

This study investigated the effect of an FSG on QoL, experienced burdens, coping strategies, and resilience of family members of PMIO. First, the main findings of this study suggest that FSGs help to (further) reduce the self-blame of family members confronted with a mentally ill relative who offended. However, in examining the norm scores, participants in the current study showed both in pre- and post-treatment mean scores that were close to the norm. A possible explanation for this finding may be that the participants in this study already had a long history of coping with the situation they were confronted with, and were able to overcome self-blame over the course of time (Moses, 2010). Moreover, some studies highlight the fact that family support may help to reduce feelings of self-blame (Moses, 2010; Nordström et al., 2006; Ridley et al., 2014). Second, family members showed improved emotional well-being following attendance of the sessions. This finding may be due to the particular model of the FSG (i.e. in terms of its format and content) which was designed to foster a context that enabled family members to disclose their emotions. This feature is important as many family members of PMIO are confronted with a diverse range of emotions, 
a double stigma, and poorer well-being, which warrants particular attention during treatment (Moses, 2010; Ridley et al., 2014; Rowaert et al., 2017; Tsang et al., 2002). Moreover, many participants were listened to by others (i.e., therapists and family members) for the first time, which may also have positively influenced their emotional well-being. As shown by other researchers, many family members frequently receive little support from friends, family members or professionals for their experienced burdens (Absalom-Hornby et al., 2011; Pearson \& Tsang, 2004; Nordström et al., 2006). Third, participants experienced less loss of control over their lives. This finding may be partly explained by the fact that peer support within the FSG may provide families with a novel understanding of their situation. Peer support is reported to promote changes in family members' lives since as participants are viewed as consultants, which thus offers a feeling of support and recognition for their situation (Asen, 2002; McFarlane, 2002). Furthermore, attendance increases the social support network as participants encourage each other, reinforce strengths, and develop coping strategies through the sharing of their stories (McFarlane, 2002). Although we have found statistically significant results based on the scores of the ZBI, no norm scores are available, which questions the clinical significance of the results. Yet, when comparing the total burden score to that reported in other research, the population of our study showed moderate burden scores (Stagg \& Larner, 2015).

In addition, the researchers anticipated improvements in the scores from the RS-nl as the sessions specifically focused on participants' strengths. However, participants in this study showed a lower resilience than the norm both during, pre- and post-treatment, and no improvement was found. In contrast, the total burden score decreased. This finding suggests that four sessions may be sufficient to experience less burden and improve emotional wellbeing, but that additional sessions or a longer support period are required to influence resilience. As described by other studies, family interventions are important to empower 
families, to explore family members' fears, and to assist them in developing new and hopeful narratives (Absalom-Hornby et al., 2011; Moses, 2010; Nordström et al., 2006; Saleeby, 1996). Our results are in line with the research studies of Dixon and colleagues $(2011 ; 2001)$, showing that family interventions may support family members in better coping with emotional problems and improve their well-being.

Finally, it is important to acknowledge some limitations of this study, warranting the generalizability of our results. Particularly given the small sample size, the study might be underpowered and due to the lack of a control group, it cannot be decisively concluded that the results obtained were due to an effect of the treatment and/or variables. Further, a selection bias may be present, as most family members were recruited from non-profit organisations for family members of persons with a mental illness. Only a minority of participants from other organisations contacted the research team. Moreover, the participants had to take contact with the researcher themselves, which perhaps caused difficulties. The latter could for many family members be a big step to achieve, as they have become during time mistrustful in contacting professionals. Therefore, it may be suggested that family members who already had a long history of taking care of a mentally ill offender were able to speak more candidly about the situation they were confronted with. Notwithstanding these limitations, the results seem to support the hypothesis that an FSG can support and empower family members in terms of managing their emotional experiences and developing coping strategies. However, it is necessary that future research utilise more rigorous designs and control groups in order to examine the generalisability of the findings. Based on other studies, future research should focus more on the general well-being of family members of persons with a mental illness who offended (Dixon et al., 2011). 


\section{Acknowledgements}

The FSGs were carried out in cooperation with Lies Vandamme and Michiel Cuypers, two master-level students in Special Needs Education (Ghent University). This study is funded by the Special Research Fund of Ghent University for concerted research actions from 2014 till 2019 entitled: 'Developing multidisciplinary strengths-based strategies for mentally ill offenders'. First we would like to thank the family members who were willing to participate in this study during 3 months. Second, we would also like to thank both the psychiatrists and the medical resident in Psychiatry from the Department of Psychiatry and Medical Psychology at Ghent University Hospital.

\section{Funding}

The study is funded by the Special Research Fund of Ghent University for concerted research actions.

\section{References}

Absalom, V., McGovern, J., Gooding, P.A., \& Tarrier, N. (2010). An assessment of patient need for family intervention in forensic services and staff skill in implementing family interventions. The Journal of Forensic Psychiatry and Psychology, 21(3), 350-365. Doi: 10.1080/14789940903426893.

Absalom-Hornby, V., Gooding, P., Tarrier, N. (2011). Coping with schizophrenia in forensic services: the needs of relatives. Journal of Nervous and Mental Disease, 199(6), 398402. Doi: 10.1097/NMD.0b013e31821cd394

Asen, E. (2002). Multiple family therapy: an overview. Journal of Family Therapy, 24(1), 316. Doi: $10.1111 / 1467-6427.00197$

De Vries, J., \& Van Heck, G.L. (1996). WHOQOL-BREF. Tilburg: Universiteit van Tilburg. 
Dixon, L. B., Lucksted, A., Medoff, D. R., Burland, J., Stewart, B., Lehman, A. F. .., \& Murray-Swank, A. (2011). Outcomes of a Randomized Study of a Peer-Taught Familyto-Family Education Program for Mental Illness. Psychiatric Services, 62(6), 591-597. doi: 10.1176/ps.62.6.pss6206_0591

Dixon, L., McFarlane, W. R., Lefley, H., Lucksted, A., Cohen, M., Falloon, I. ..., \& Sondheimer, D. (2001). Evidence-Based Practices for Services to Families of People with Psychiatric Disabilities. Psychiatric Services, 52(7), 903-910

Ferriter, M., \& Huband, N. (2003). Experiences of parents with a son or daughter suffering from schizophrenia. Journal of Psychiatric Mental Health Nursing, 10(5), 552-560. Doi: 10.1046/j.1365-2850.2003.00624.x

Garnefski, N., \& Kraaij, V. (2007). The Cognitive Emotion Regulation Questionnaire Psychometric Features and Prospective Relationships with Depression and Anxiety in Adults. European Journal of Psychological Assessment, 23(3), 141-149. Doi: 10.1027/1015-5759.23.3.141.

Garnefski, N., Kraaij, V., \& Spinhoven, P. (2006, version 1.03). Manual for the use of the Cognitive Emotion Regulation Questionnaire (Dutch version). Leiderdorp, The Netherlands: DATEC.

Geelan, S., \& Nickford, C. (1999). A survey of the use of family therapy in medium secure units in England and Wales. The Journal of Forensic Psychiatry, 10(2), 317-324. Doi: $10.1080 / 09585189908403685$.

Heimans, H., Vander Beken, T., Schipaanboord, A.E. (2015). Eindelijk een echte nieuwe en goede wet op de internering? Deel 1: De gerechtelijke fase. Rechtskundig Weekblad, 79(27), 1043-1064.

Mapi Research Trust (2014). Zarit Burden Interview version 1.0 - Scaling and scoring version 3.0. Lyon: Mapi Research Trust. 
Marsh, D.T., \& Johnson, D.L. (1997). The family experience of mental illness: implications for intervention. Professional Psychology Research and Practice, 28(3), 229-237. Doi: $10.1037 / 0735-7028.28 .3 .229$

McCann, G., McKeown, M., Porter, I. (1996). Understanding the needs of relatives of patients within a special hospital for mentally disordered offenders: a basis for improved services. Journal of Advanced Nursing, 23(2), 346-352. Doi: 10.1111/j.13652648.1996.tb02677.x

McFarlane, W.R. (2002). Multifamily Groups in the treatment of severe psychiatric disorders. New York/London: The Guilford Press.

Moses, T. (2010). Exploring Parents' Self-Blame in Relation to Adolescents' Mental Disorders. Family Relations, 59(2), 103-120. Doi: 10.1111/j.1741-3729.2010.00589.x

Nordström, A., Kullgren, G., Dahlgren, L. (2006). Schizophrenia and violent crime: the experience of parents. International Journal of Law and Psychiatry, 29(1), 57-67. Doi: 10.1016/j.ijlp.2004.07.002

Pearson, V., Tsang, H.W. (2004). Duty, burden, and ambivalence: families of forensic psychiatric patients in Hong Kong. International Journal of Law and Psychiatry, 27(4), 361-374. Doi: 10.1016/j.ijlp.2003.08.001

Portzky, M., Wagnild, G., De Bacquer, D., \& Audenaert, K. (2010). Psychometric evaluation of the Dutch Resilience Scale RS-nl on 3265 healthy participants: a confirmation of the association between age and resilience found with the Swedish version. Scandinavian Journal of Caring Sciences, 24(suppl. 1), 86-92. Doi: 10.1111/j.14716712.2010.00841.x

Rankin, E.D., Haut, M.W., Keefover, R.W., \& Franzen, M.D. (1994). The establishment of clinical cutoffs in measuring caregiver burden in dementia. Gérontologist, 34(6), 828832. Doi: $10.1093 /$ geront/34.6.828 
Ridley, J., McKeown, M, Machin, K., Rogengard, A., Little, S., Briggs, S, Jones, F., \& Deypurkaystha, M. (2014). Exploring Family Caregiver Involvement in Forensic Mental Health Services. Scotland: Support in Mind Scotland, University of Central Lancashire and Forensic Mental Health Services Managed Care Network, pp. 1-87 (report).

Rowaert, S., Hanssens, F., Audenaert, K., Vandevelde, S. \& Lemmens, G. (submitted). A Family Support Group for family members of mentally ill offenders: concepts and therapeutic processes.

Rowaert, S., Vandevelde, S., Lemmens, G., Vanderplasschen, W., Vander Beken, T., Vander Laenen, F., \& Audenaert, K. (2016). The role and experiences of family members during the rehabilitation of mentally ill offenders. International Journal of Rehabilitation Research, 39(1), 11-19. Doi: 10.1097/MRR.0000000000000152

Rowaert, S., Vandevelde, S., Lemmens, G., \& Audenaert, K. (2017). How family members of mentally ill offenders experience the internment measure and (forensic) psychiatric treatment in Belgium: A qualitative study. Journal of Law and Psychiatry, http://dx.doi.org/10.1016/j.ijlp.2017.05.003.

Saleeby, D. (1996). The strengths perspective in social work practice: Extensions and cautions. Social Work, 41(3), 296-305. Doi: 10.1093/sw/41.3.296.

Stagg, B., \& Larner, A. J. (2015). Zarit Burden Interview: pragmatic study in a dedicated cognitive function clinic. Progress in Neurology and Psychiatry, 19(4), 23-27. doi: 10.1002/pnp.390

THE WHOQOL GROUP (1995). The World Health Organization Quality of Life Assessment (WHOQOL): position paper from The World Health Organization. Social Sciences \& Medicine, 41(10), 1403-1409. 
THE WHOQOL GROUP (1998). WHOQOL User Manual. Switzerland: World Health Organization.

Tsang, H.W., Pearson, V., Yuen, C.H. (2002). Family needs and burdens of mentally ill offenders. International Journal of Rehabilitation Research, 25(1), 25-32. Doi: 10.1097/00004356-200203000-00004

Vandevelde, S., Soyez, V., Vander Beken, T., De Smet, S., Boers, A., \& Broekaert, E. (2011). Mentally ill offenders in prison: The Belgian case. International Journal of Law and Psychiatry, 34(1), 71-78. doi: 10.1016/j.ijlp.2010.11.011

Wasserman, S., Weisman de Mamani, A., \& Suro, G. (2012). Shame and guilt/self-blame as predictors of expressed emotion in family members of patients with schizophrenia. Psychiatric Research, 196(1), 27-31. Doi: 10.1016/j.psychres.2011.08.009.

Zarit, S.H., Reever, K.E., Bach-Peterson, J. (1980). Relatives of the impaired elderly, correlates of feelings of burden. Gérontologist, 20(6), 649-655. Doi: 10.1093/geront/20.6.649

Zarit, S., Todd, P.A., Zarit, J.M. (1986). Subjective burden of husbands and wives as caregivers: a longitudinal study. Gérontologist, 26(3), 260-266. Doi: $10.1093 /$ geront/26.3.260

\footnotetext{
' In Belgium the internment measure is defined as: 'a safety measure to protect society and that simultaneously aims to ensure that the mentally ill offender is provided with the care his/her condition requires in view of his/her reintegration into society' (Heimans, Vander Beken, \& Schipaanboord, 2015, p. 1051, translation by the authors).
} 